\title{
Photolytic removal of DBPs by medium pressure UV in swimming pool water
}

\author{
Hansen, Kamilla Marie Speht; Zortea, R.; Piketty, A.; Rodriguez Vega, S.; Andersen, Henrik Rasmus
}

Published in:

Science of the Total Environment

Link to article, DOI:

10.1016/j.scitotenv.2012.11.064

Publication date:

2013

Link back to DTU Orbit

Citation (APA):

Hansen, K. M. S., Zortea, R., Piketty, A., Rodriguez Vega, S., \& Andersen, H. R. (2013). Photolytic removal of DBPs by medium pressure UV in swimming pool water. Science of the Total Environment, 443, 850-856. https://doi.org/10.1016/j.scitotenv.2012.11.064

\section{General rights}

Copyright and moral rights for the publications made accessible in the public portal are retained by the authors and/or other copyright owners and it is a condition of accessing publications that users recognise and abide by the legal requirements associated with these rights.

- Users may download and print one copy of any publication from the public portal for the purpose of private study or research.

- You may not further distribute the material or use it for any profit-making activity or commercial gain

- You may freely distribute the URL identifying the publication in the public portal 


\title{
Photolytic removal of DBPs by medium pressure UV in swimming pool water
}

\author{
Kamilla M.S. Hansen ${ }^{a}$, Raissa Zortea ${ }^{b}$, Aurelia Pikettyc, Sergio \\ Rodriguez Vegad, and Henrik Rasmus Andersena*
}

\footnotetext{
${ }^{a}$ Department of Environmental Engineering, Technical University of Denmark, Denmark.

${ }^{\mathrm{b}}$ Department of Land, Environment and Geotechnology Engineering, Polytechnic University of Turin, Italy.

${ }^{c}$ Institute of Chemistry, Industrial and Chemical Engineering and Technology (INPENCIACET), National Polytechnic Institute of Toulouse, France.

${ }^{\mathrm{d}}$ Chemical engineering, Complutense University of Madrid, Spain.

*Corresponding author: e-mail address: Henrik@ndersen.net, telephone number: +454525 1583, postal address: DTU Environment, Miljoevej 113, 2800 Lyngby, Denmark.
}

Article published in Science of the Total Environment 2013, 443, pp. 850-856.

http://dx.doi.org/10.1016/j.scitotenv.2012.11.064 
Hansen et al. 2013. Science of the Total Environment, 443, pp. 850-856.

http://dx.doi.org/10.1016/j.scitotenv.2012.11.064

\begin{abstract}
Medium pressure UV is used for controlling the concentration of combined chlorine (chloramines) in many public swimming pools. Little is known about the fate of other disinfection by-products (DBPs) in UV treatment. Photolysis by medium pressure UV treatment was investigated for 12 DBPs reported to be found in swimming pool water: chloroform, bromodichloromethane, dibromochloromethane, bromoform, dichloroacetonitrile, bromochloroacetonitrile, dibromoacetronitrile, trichloroacetonitrile, trichloronitromethane, dichloropropanone, trichloropropanone, and chloral hydrate. First order photolysis constants ranged 26-fold from $0.020 \mathrm{~min}^{-1}$ for chloroform to $0.523 \mathrm{~min}^{-1}$ for trichloronitromethane. The rate constants generally increased with bromine substitution.

Using the UV removal of combined chlorine as an actinometer, the rate constants were recalculated to actual treatment doses of UV applied in a swimming pool. In an investigated public pool the UV dose was equivalent to an applied electrical energy of $1.34 \mathrm{kWh} \mathrm{m}^{-3} \mathrm{~d}^{-1}$ and the UV dose required to removed $90 \%$ of trichloronitromethane was $0.4 \mathrm{kWh} \mathrm{m}^{-3} \mathrm{~d}^{-1}$, while $2.6 \mathrm{kWh} \mathrm{m}^{-3} \mathrm{~d}^{-1}$ was required for chloral hydrate and the bromine containing haloacetonitriles and trihalomethanes ranged from 0.6 to $3.1 \mathrm{kWh} \mathrm{m}^{-3} \mathrm{~d}^{-1}$. It was predicted thus that a beneficial side-effect of applying UV for removing combined chlorine from the pool water could be a significant removal of trichloronitromethane, chloral hydrate and the bromine containing haloacetonitriles and trihalomethanes.
\end{abstract}

Keywords UV treatment; disinfection by-products (DBP); Electrical energy per order (EEO); swimming pool; photolysis.

Abbreviations: THM, trihalomethane; HAN, haloacetonitrile; DBP, disinfection by product; EEO, electrical energy per order; EED, electrical energy dose;

\title{
1 Introduction
}

For more than 100 years chlorine has been the preferred disinfectant to ensure the hygienic quality of swimming pool water. Chlorine is the common name for hypochlorous acid $(\mathrm{HOCl})$, which is formed by gaseous chlorine reacting with water. The hypochlorous acid dissociates in water to hypochlorite $\left(\mathrm{OCl}^{-}\right)\left(\mathrm{pK}_{\mathrm{a}}=7.5\right)$ and the sum of $\mathrm{HOCl}$ and $\mathrm{OCl}^{-}$are known as free chlorine. Hypochlorous acid is significantly more effective than hypochlorite as a bactericide, in preventing cysts and the spreading of spores and inactivating viruses (White, 1992).

It is well documented that chlorine reacts with organic and inorganic matter released from bathers (sweat, saliva, urine, skin residues) to form chlorinated disinfection by-products (DBPs). A recent study identified over 100 DBPs in pool water and reported a higher number of nitrogen-containing DBPs than typically found in chlorinated drinking water with several of the chemicals not identified in drinking water (Richardson et al., 2010). The major concern regarding DBP formation is their effects on human health. Since some DBPs formed in swimming pools are also found in chlorinated drinking water, some studies about 
Hansen et al. 2013. Science of the Total Environment, 443, pp. 850-856.

http://dx.doi.org/10.1016/j.scitotenv.2012.11.064

genotoxicity, carcinogenicity and health effect risks have been undertaken. However, swimming pool waters are significantly more genotoxic than their source tap water (Liviac et al., 2010) which is likely due to the nitrogen-rich precursors released by the bathers. Furthermore, a recent study on bladder cancer found a clear increased risk associated with chlorination by-products in drinking water and indicates that the use of swimming pools further increased the risk (Villanueva et al., 2007).

A common condition affecting swimmers is eye irritation and various compounds such as chlorine, chloramines, haloketones and haloacetic acids have been identified as irritants (Chiswell and Wildsoet, 1989; Erdinger et al., 1998; Zwiener et al., 2007). Erdinger et al. (1998) concluded that the degree of eye irritation resulting from swimming pool waters can only be explained by considering the effects and synergistic action of a number of DBPs in the presence of chlorine. Another effect of DBPs on swimmers is irritation of the respiratory passage and trichloramine has been suggested as the causative compound. Several studies on the association of $\mathrm{NCl}_{3}$ with respiratory irritation or asthma have been carried out (Bernard et al., 2007; Goodman and Hays, 2008; Hery et al., 1995; Massin et al., 1998; Thickett et al., 2002) however there is still a lack of evidence with which to make a definite conclusion. A recent study performed an in vitro air exposure test using the human alveolar epithelial carcinoma cell line A-549 to conclude that the concentration of $\mathrm{NCl}_{3}$ alone could not explain the inflammatory effect of air from an indoor swimming pool and that other volatile DBPs must also be contributing to the observed effects (Schmalz et al., 2011).

Due to the lack of alternatives, the continued use of chlorine as a disinfectant is the most realistic immediate future scenario for public swimming pools. Therefore there is a need to find alternative methods by which to ensure acceptable water quality in the public swimming pools which could be a combination of removing DBP precursors and DBPs themselves. The load of DBP precursors can be reduced significantly by ensuring effective pre-swim hygiene (showering) (Keuten et al, 2012). When DBP precursors are in the water a potential method improvement suggested in literature is to lower the $\mathrm{pH}$ in order to reduce the formation of trihalomethanes (THMs)(Kristensen et al., 2007). However, recent studies reported an increased formation of the more toxic DBP group, haloacetonitriles (HANs), when decreasing the pH (Hansen et al., 2012a; Hansen et al., 2012b).

One way to remove combined chlorine including $\mathrm{NCl}_{3}$ is treatment with medium pressure (MP) UV irradiation. In 1976, the first MP UV system was installed in a swimming pool in Denmark and today there are estimated to be 1000-2000 installations in public swimming pools in Europe (Povl Kaas, Personal communication). UV light at 222, 254, 288 $\mathrm{nm}$ is able to photo degrade inorganic chloramines and showed little or no $\mathrm{pH}$ dependence ( $\mathrm{Li}$ and Blatchley, 2009). A study using MP UV treatment in full stream found up to $32 \%$ reduction of $\mathrm{NCl}_{3}$ in air (Cassan et al., 2011). While another study with MP UV treatment applied to a side stream of the filter return flow reported a decrease in the water concentration of combined chlorine greater than $50 \%$ (Kristensen et al., 2009; Kristensen et al., 2010). However, studies of UV photo degradation of other DBPs are very limited. 
Hansen et al. 2013. Science of the Total Environment, 443, pp. 850-856.

http://dx.doi.org/10.1016/j.scitotenv.2012.11.064

UV treatment in a swimming pool has been reported by Cassan et al. (2006) to increase THM levels in the pool while Beyer et al. (2004) reported a decrease in THM levels in a similar study. In a long term study including matched control periods with and without UV treatment in a public pool, Kristensen et al. (2009) showed no effect on THM levels in a swimming pool treated by several types of UV treatment. A mechanism that explain how THM may increase by UV treatment in some cases is given by Glauner et al. (2005) who describe from a laboratory batch experiment of UV treatment of pool water that an increased THM formation potential was induced by the UV treatment when UV treated samples were chlorinated after UV exposure. In public swimming pools chlorine will always be present and since photolysis of chlorine creates radicals (Jin et al., 2011; Sichel et al., 2011) it is possible that some degradation of DBPs may occur by reactions with radicals produced by photolysis of hypochlorite.

The objective of this research was to investigate the photo degradation of 12 of the most common DBPs besides chloramines by UV irradiation with an MP lamp. The investigated DBPs were chloroform, bromodichloromethane, dibromochloromethane, bromoform, dichloroacetonitrile, bromochloroacetonitrile, dibromoacetronitrile, trichloroacetonitrile, trichloronitromethane, dichloropropanone, trichloropropanone, and chloral hydrate. To investigate the possible effect of radical reactions from photolysis of hypochlor experiments were performed with and without the presence of free chlorine. We avoided the possibility of formation of any of the investigated DBP from organic matrix in swimming pool water by performing the experiment on pure chemicals in solution of purified water and we tested the stoichiometrically possible formation of THM from the HANs and chloral hydrate after UV treatment by performing separate experiments with these DBPs.

From the data obtained the first order kinetic constant and the treatment level required to remove $90 \%$ of each of the 12 DBP was determined. Furthermore, photolysis of naturally occurring combined chlorine in a public swimming pool was used as an actinometer to compare the UV doses delivered in a full scale UV installation and the laboratory setup. Thus the significance of the actual typical UV treatment dose applied in a swimming pool could be compared to the dose required for photolysis of each of the 12 DBPs.

\section{Material and Methods}

\subsection{Reagents}

All chemicals and standard solutions were of analytical grade purchased from Sigma-Aldrich.

\subsection{Analysis of trihalomethanes and haloacetonitriles}

The analyses were performed as previously published in (Hansen et al., 2012a). In brief free chlorine was quenched by adding ammonium chloride solution to the vials before they were filled head-space-free with sample. The samples were analyzed the same day by Purge and 
Hansen et al. 2013. Science of the Total Environment, 443, pp. 850-856.

http://dx.doi.org/10.1016/j.scitotenv.2012.11.064

Trap (purge temperature $=30{ }^{\circ} \mathrm{C}$, Velocity XPT Purge and Trap Sample Concentrator, Teledyne Tekmar, with autosampler: AQUATek 70, Teledyne Tekmar) coupled with a GCMS (HP 6890 Series GC System, 5973 Mass selective detector, Hewlett Packard). This method was also used for the detection of trichloronitromethane, dichloropropanone, and trichloropropanone.

\subsection{Analysis of chloral hydrate and haloacetonitriles}

For the analysis of the chloral hydrate and HANs a modified version of the EPA 551.1 method was used. A $40 \mathrm{~mL}$ borosilicate glass vial was filled with sample without head-space and the samples were stored until the end of the day where all samples were analysed.

To make space in the vial $7 \mathrm{~mL}$ of each sample was removed and methyl-tert-butyl ether, internal standard (bromofluorobenzene) and buffer with quenching agent $\left(\mathrm{Na}_{2} \mathrm{HPO}_{4} / \mathrm{KH}_{2} \mathrm{PO}_{4} / \mathrm{Na}_{2} \mathrm{SO}_{3}\right)$ were added to the vial. Followed by two drops of a colourant (14.85 $\mathrm{g} \mathrm{L}^{-1}$ 1,10-phenanthrolie $\cdot \mathrm{H}_{2} \mathrm{O}$ and $6.95 \mathrm{~g} \mathrm{~L}^{-1}$ ferrosulphate $\cdot 7 \mathrm{H}_{2} \mathrm{O}$ ) and $\mathrm{Na}_{2} \mathrm{SO}_{4}$. The vials were shaken for $30 \mathrm{~min}$ before the methyl-tert-butyl ether phase was transferred to a GC vial and analyzed on a GC-MS (GC 6890N - MSD 5973N, Agilent Technologies). The samples were analysed on the day of collection or stored in the refrigerator for the following day. Details on the method can be found in the Supplementary material.

\subsection{Analysis of chlorine and combined chlorine}

The concentration of free and total chlorine was measured with a photometer (DR 2800, Hach Lange) using the colorimetric method based on oxidation of diethyl-pphenylenediamine (DPD) with or without addition of iodide.

\subsection{UV treatment}

Batch experiments were performed in a quasi-collimated beam apparatus. The principle of this is illustrated in Fig. 1a. A doped medium pressure lamp (SR HUV700 (European patent: EP1463091A2), 700W, Scan Research A/S, Denmark) with enhanced emission in the area with low wavelength was utilized (Fig. 1b). The lamp was turned on for at least 20 min prior to experiments to ensure constant light output and spectral composition. The distance from the lamp to the centre of the bottom of the petri dish $(\mathrm{d}=90 \mathrm{~mm})$ was $35 \mathrm{~cm}$ and the treated volume was $120 \mathrm{~mL}$. The lamp and the petri dish were separated with a board in which a 280 $\mathrm{mm}$ tube with inner diameter of $76 \mathrm{~mm}$ was imbedded in order to collimate the light (see illustration in Fig. 1a). The sample was covered by a lid of pure quartz glass. During the irradiation the samples were gently stirred with the use of a magnetic stirrer. Experiments were performed at $26{ }^{\circ} \mathrm{C}$ and due to an effective air exchange the samples never increased more than $5{ }^{\circ} \mathrm{C}$ in temperature during treatment. After irradiation of water samples in predetermined time intervals, analysis of DBPs was performed. The irradiation from the lamp was checked each day by removal of monochloramine, which was produced by reacting 0.75 $\mathrm{g}$ of ammonium chloride and $5 \mathrm{~mL}$ of chlorine $\left(50 \mathrm{~g} \mathrm{~L}^{-1}\right)$ in MilliQ water buffered with 
Hansen et al. 2013. Science of the Total Environment, 443, pp. 850-856.

http://dx.doi.org/10.1016/j.scitotenv.2012.11.064

phosphate buffer at $\mathrm{pH}=6.0$ overnight at $20^{\circ} \mathrm{C}$. The UV light was measured in radiation exposure minutes.

a)

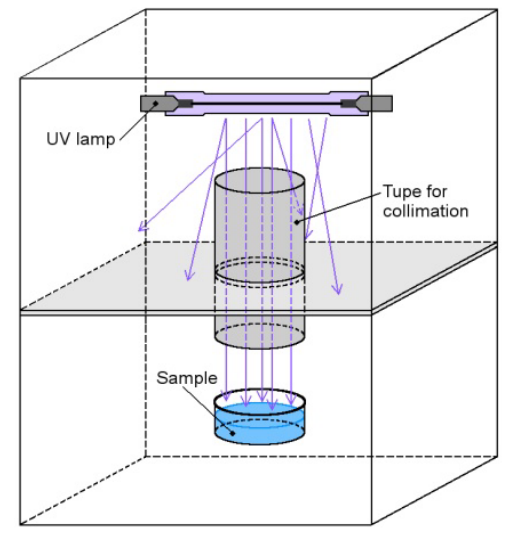

b)

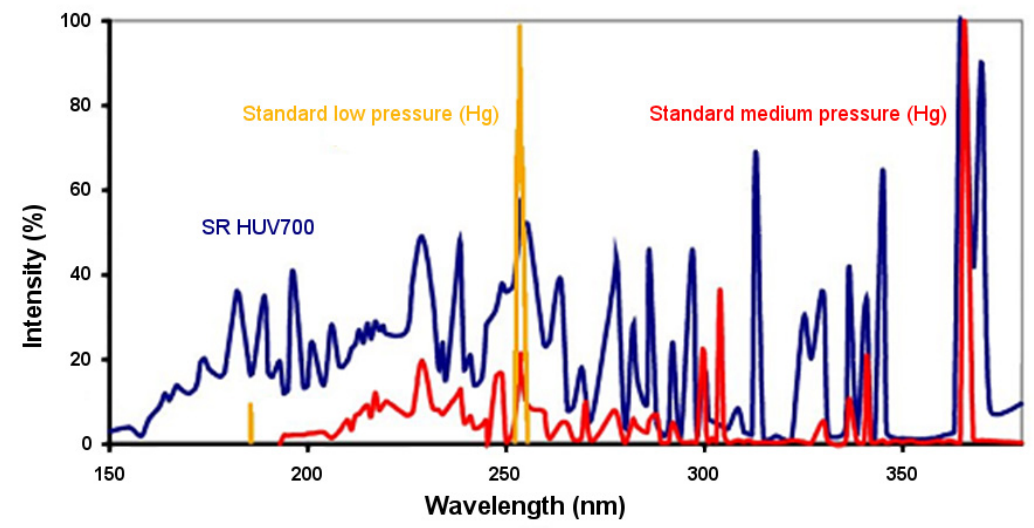

Fig. 1. a) Schematic description of the collimated beam irradiation apparatus. b) The emission spectra for a standard mercury low pressure (yellow) and a medium pressure (red) UV lamp compared to the used medium pressure UV lamp based on doped halogens (SR HUV700, blue).

\subsection{Characterization of the UV lamp}

The SR HUV700 lamp used in the collimated beam setup is identical to that installed in a warm water pool $\left(32{ }^{\circ} \mathrm{C}\right)$ in Gladsaxe swimming pool. The volume of the warm water pool is $50 \mathrm{~m}^{3}$ and the hydraulic resident time is $0.5 \mathrm{~h}$. The UV treatment system in Gladsaxe consisted of $4 \mathrm{UV}$ lamps placed in a side stream of the recirculation flow of $25 \mathrm{~m}^{3} \mathrm{~h}^{-1}$ (about $25 \%$ of recirculation flow to the filters). A full and detailed description of the UV-reactor and water treatment systems in Gladsaxe swimming pool can be found in Kristensen et al. (2009) and Kristensen et al. (2010).

The figures-of-merit, electrical energy per order (EEO) is recommended by the Commission on Photochemistry, International Union of Pure and Applied Chemistry in order to describe photodegradation of compounds (Bolton, 2010) and thus EEO for free and combined chlorine was determined to characterize the UV system in Gladsaxe. The EEO is defined as the electrical energy consumed per unit volume of water treated required for $90 \%$ removal of the investigated compound (Bolton, 2010). The water flow through the UV system and the electrical energy consumption for the treatment as determined by the number of lamps turned on in the UV system were varied to achieve different UV doses. The water flow was varied between 6.4 and $49.8 \mathrm{~m}^{3} \mathrm{~h}^{-1}$ and the number of lamps between 2 and 12 (1.4$8.4 \mathrm{~kW})$. The concentration of the free and combined chlorine was measured before and after the UV reactors with the different applied UV doses. The normalized concentration of free and combined chlorine was plotted against the electrical energy dose, which is defined as the electrical energy $(\mathrm{kWh})$ consumed per unit volume $\left(\mathrm{m}^{3}\right)$ of water treated. The plots were used for estimation of EEO: 
Hansen et al. 2013. Science of the Total Environment, 443, pp. 850-856.

http://dx.doi.org/10.1016/j.scitotenv.2012.11.064

$$
\log \left(\frac{\mathrm{C}_{\text {out }}}{\mathrm{C}_{\text {in }}}\right)=\frac{-1}{\mathrm{EEO}} \cdot \mathrm{EED}
$$

where $\mathrm{C}_{\text {in }}$ and $\mathrm{C}_{\text {out }}$ are the concentrations of the inflow and outflow, respectively, EED is the electrical energy dose in $\mathrm{kWh} \mathrm{m}^{-3}$ and EEO is the electrical energy per order.

The effectiveness of the UV lamp in the collimated beam setup was determined in the same manner. Water from the warm water pool in Gladsaxe was collected in 1L glass bottles filled about $10 \mathrm{~cm}$ below the surface of the pool (October $10^{\text {th }}, 2011$ ) and the removal of combined chlorine with the collimated beam setup was measured. The measured removal of combined chlorine was then used to convert the treatment time of the collimated beam setup to the treatment equivalent electrical energy dose in the full scale UV system.

\subsection{Experiments}

For the experiments aqueous solutions buffered with phosphate $(\mathrm{pH}=7.2,2.5 \mathrm{mM}$ phosphate) of chloral hydrate and THMs were freshly prepared from pure compounds while the HANs were only available as a mixture (including trichloronitromethane, dichloropropanone, trichloropropanone) in acetone (EPA 551B halogenated volatiles mix, Sigma-Aldrich). The aims of the experiments performed were to investigate a) the photolytic removal of the investigated compound from a mixture, b) the photolytic removal of chloroform from a mixture of THMs, c) the possible formation of chloroform during UV irradiation of chloral hydrate and HANs, and d) the effect of free chlorine.

The photolytic removal experiment was performed on a mixture with $200 \mu \mathrm{g} \mathrm{L}^{-1}$ of chloral hydrate, $150 \mu \mathrm{g} \mathrm{L}^{-1}$ of THMs and $100 \mu \mathrm{g} \mathrm{L}^{-1}$ of HANs. The concentration of the DBPs is in the high end of reported concentrations in swimming pools in the guideline from WHO (WHO, 2006). The samples were exposed to UV for varying durations. Control experiments were performed without exposure to UV light but otherwise handled as treated samples. The photolytic removal of chloroform was investigated by exposing a solution of $150 \mu \mathrm{g} \mathrm{L}^{-1}$ THMs to UV light for 30, 60 and $90 \mathrm{~min}$.

The experiments conducted in order to determine the possible formation of chloroform during UV treatment utilized a solution of $200 \mu \mathrm{g} \mathrm{L}^{-1}$ chloral hydrate or $100 \mu \mathrm{g} \mathrm{L}^{-1}$ HANs and a UV exposure time of $20 \mathrm{~min}$.

To investigate the effect of the presence of free chlorine two experiments were conducted using a mixture of all the studied compounds. In the first experiment $5 \mathrm{mg} \mathrm{L}^{-1}$ of chlorine (Sodium hypochlorite $\sim 10 \%$, Sigma-Aldrich) was added to a sample followed by exposure to UV for $3 \mathrm{~min}$. The second experiment aimed to simulate repeated treatments in a continuous system by adding $5 \mathrm{mg} \mathrm{L}^{-1}$ of chlorine followed by $3 \mathrm{~min} \mathrm{UV}$ irradiation in 3 steps. 
Hansen et al. 2013. Science of the Total Environment, 443, pp. 850-856.

http://dx.doi.org/10.1016/j.scitotenv.2012.11.064

\section{Results and discussion}

\subsection{Lamp characterization and comparison to full scale system}

The characterisation of UV lamps is traditionally performed by determining the fluence (UV dose, in $\mathrm{mJ} \mathrm{cm}^{-2}$ ). However, this works best for low pressure lamps where the light is primarily emitted at $254 \mathrm{~nm}$ and the quantum yields for the different actinometers are well known. The determination of fluence for medium pressure lamps which have broad spectral outputs is considerably more complicated, requiring the use of a table of wavelength spectral specific absorbances and quantum yields. This is particularly complicated for the lamp used in this study which has a non-standard spectral output due to that the burner contained a doped halogen mixture as opposed to the traditional mercury vapour. The international union of pure and applied chemistry (IUPAC) advises that the characterisation of UV systems for removal of chemicals be conducted by either direct photolysis or advanced oxidation by energy consumption (Figure-of-Merit electrical energy per order, EEO). Like fluence, EEO depends on fundamental photochemical parameters (Stefan and Bolton, 2005). Companies that supply UV systems for swimming pools and swimming pools with UV installations know the energy consumption and efficiency to remove combined chlorine of their UVsystems. However, they generally do not know the UV fluence delivered to the treated water which determines the degree of chemical reactions that occur. In many cases the rated minimum fluence of a UV unit is factory determined as the same systems are used for drinking water disinfection which is not usable for quantifying the photolysis of chemicals in the water. The minimum fluence describes the irradiation intensity delivered on the inner wall of the UV reactor which is relevant for disinfection. The fluence delivered to the water in the reactor determines the effectiveness of chemical conversions that the unit can perform.

Free chlorine was seen to be removed at a greater rate (lower treatment dose) than combined chlorine by the full scale UV system (Fig. 2a). The plots of normalized concentration (in and out of the UV system) plotted against the electrical energy dose (EED) were used for determination of the energy per order of removal (EEO) by least squares fitting based on Eq. 1. The EEO for free chlorine and combined chlorine in Gladsaxe swimming pool was $0.22 \mathrm{kWh} \mathrm{m}^{-3}$ and $1.0 \mathrm{kWh} \mathrm{m}^{-3}$, respectively. Thus, combined chlorine needed approximately 5 times more energy than free chlorine to achieve $90 \%$ removal.

Since in the full scale UV system the whole lamp is submerged, all UV light is radiated into the pool water. However, this is not the case for the collimated beam setup where only a small fraction of UV light that is emitted radiates into the treated water. Therefore determination of the EED utilised in the collimated beam is not as straight forward as for the UV system in Gladsaxe swimming pool. Removal of combined chlorine from the swimming pool water sample by collimate beam setup was determined and plotted as a function of irradiation time (Fig. 2b). The irradiation time to achieve $90 \%$ removal of combined chlorine was 10.5 min (Fig. 2b), corresponding to the energy dose at EEO. In Gladsaxe swimming pool (i.e. full scale treatment) the EEO for removal of combined chlorine was $1.0 \mathrm{kWh} \mathrm{m}^{-3}$. 
Hansen et al. 2013. Science of the Total Environment, 443, pp. 850-856.

http://dx.doi.org/10.1016/j.scitotenv.2012.11.064

Thus the EEO of $10.5 \mathrm{~min}$ in the collimated beam was estimated to be equal to the EEO of $1.0 \mathrm{kWh} \mathrm{m}^{-3}$ in the swimming pool and thereby $1.0 \mathrm{~min}$ irradiation time in the collimated beam setup was calculated to be equal to $0.095 \mathrm{kWh} \mathrm{m}^{-3}$ in the full scale treatment system. This estimation was used to predict the approximate value of EEO for the investigated DBPs.

\section{a) Full scale UV in Gladsaxe swimming pool}

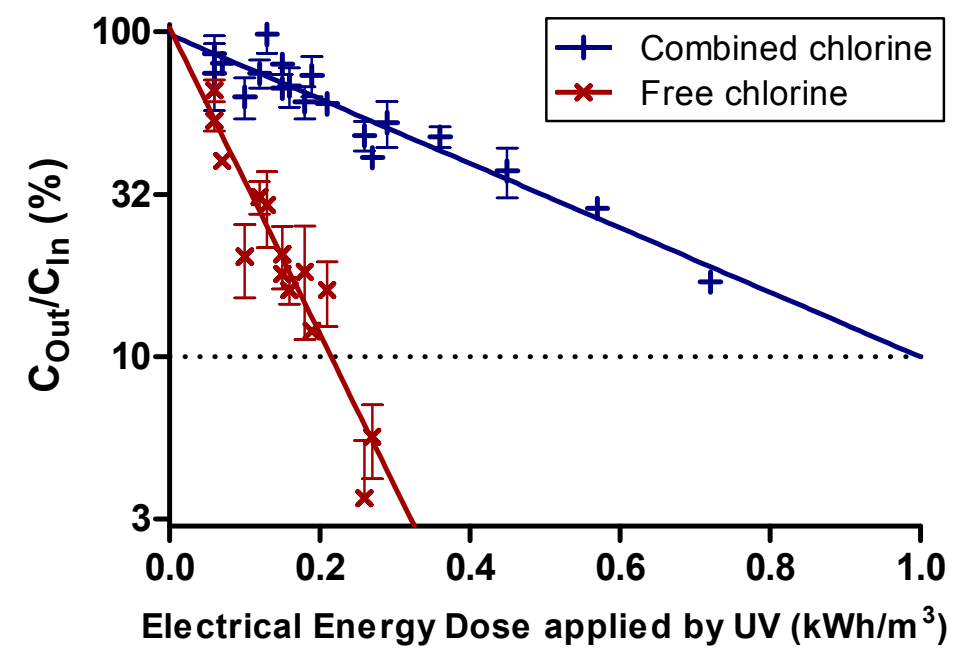

b) Collimated beam UV exposure

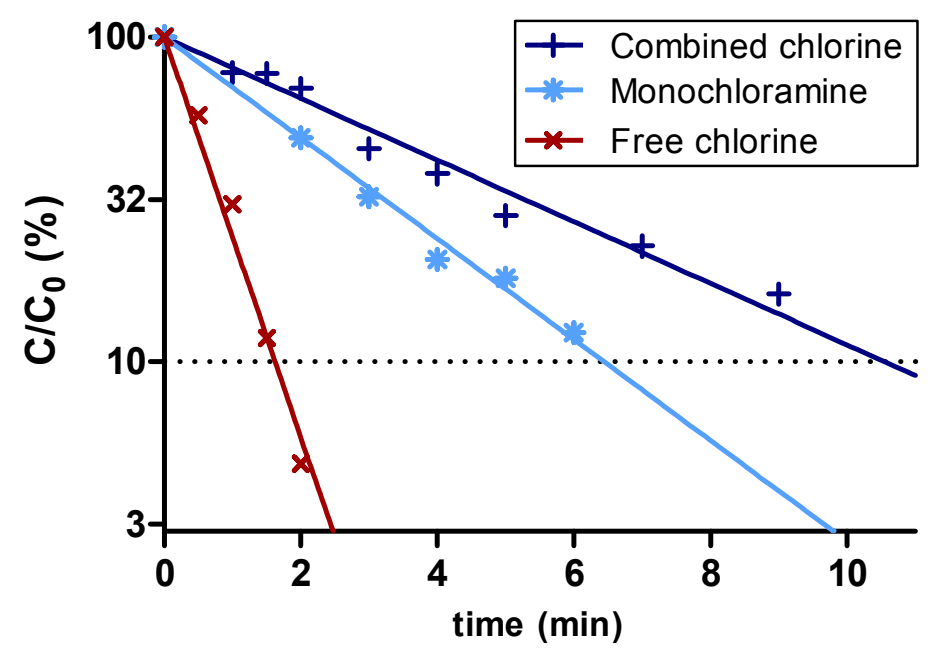

Fig. 2. Photolytic removal by UV irradiation of a) free and combined chlorine in pool water in full scale flow through system in Gladsaxe swimming pool on a side stream of the filter return flow compared to $b$ ) combined chlorine in pool water, monochloramine and free chlorine in the laboratory collimated beam UV irradiation setup. The error bars gives the standard error of the mean based on 3-7 replicates in a), while b) is made with single determinations. 
Hansen et al. 2013. Science of the Total Environment, 443, pp. 850-856.

http://dx.doi.org/10.1016/j.scitotenv.2012.11.064

Irradiation time to achieve $90 \%$ removal of the monochloramine produced was $6.4 \mathrm{~min}$, which is less than the time needed for photolysis of combined chlorine in pool water. The pool water contains organic chloramines which to some extent represents part of the combined chlorine as measured by the DPD method (Li and Blatchley, 2007). From this one can conclude that some organic chloramines are less sensitive to degradation by UV than monochloramine. The difference in sensitivity to photolysis of organic and inorganic chloramines is inconsequential for these experiments. The monochloramine solution was used only as an actinometer when performing the experiments in the laboratory setup, to ensure consistency from day to day and generally no significant change was seen between the days experiments were performed. The naturally occurring combined chlorine in the swimming pool was treated in both full scale pool and the laboratory UV systems and subsequently used to convert units of treatment doses between the two UV systems.

\subsection{Photolytic removal of DBPs with medium pressure lamp}

Results obtained upon treatment of the mixture of tested DBPs with UV light can be seen in Fig. 3(a, b, c). Control experiments were conducted under identical experimental conditions without direct exposure to UV light. Recovery of DBPs was greater than $75 \%$ in all cases, being close to $100 \%$ in the majority.

\subsubsection{Removal of trihalomethanes}

Profiles of removal efficiency for trihalomethanes with UV irradiation can be seen in Fig. 3a. The photolytic removal rate of DBPs was successfully fitted to an integrated first order kinetic expression (Eq. 2) where $\mathrm{C}$ is the concentration after treatment, $\mathrm{C}_{0}$ the initial concentration of the DBP and $\mathrm{k}$ the first order kinetic constant.

$$
\mathrm{C} / \mathrm{C}_{0}=\exp (-\mathrm{k} \cdot \mathrm{t})
$$

Kinetic constant values were obtained from the experimental data by least square fit according to Eq. 2 and can be seen in Table 1. According to these values, the presence of bromine in the molecular structure of THM remarkably increased the removal rate, since these species are more photosensitive than their chlorinated analogues (Chen et al., 2010; De Laat and Berne 2009; Lekkas and Nikolaou 2004). Therefore, the kinetic constant corresponding to bromoform $\left(0.390 \mathrm{~min}^{-1}\right)$ was the highest and chloroform $\left(0.020 \mathrm{~min}^{-1}\right)$ the lowest.

As shown in Fig. 3a removal of $80 \%$ of chloroform was achieved in $90 \mathrm{~min}$. The literature states that no removal of chloroform can be obtained with low pressure UV lamps (Nicole et al., 1991) but with high pressure lamps, some chloroform removal can be achieved (Rudra et al., 2005). Thus both medium and high pressure UV lamps are to some extent able to remove chloroform due to their polychromatic light emissions. 

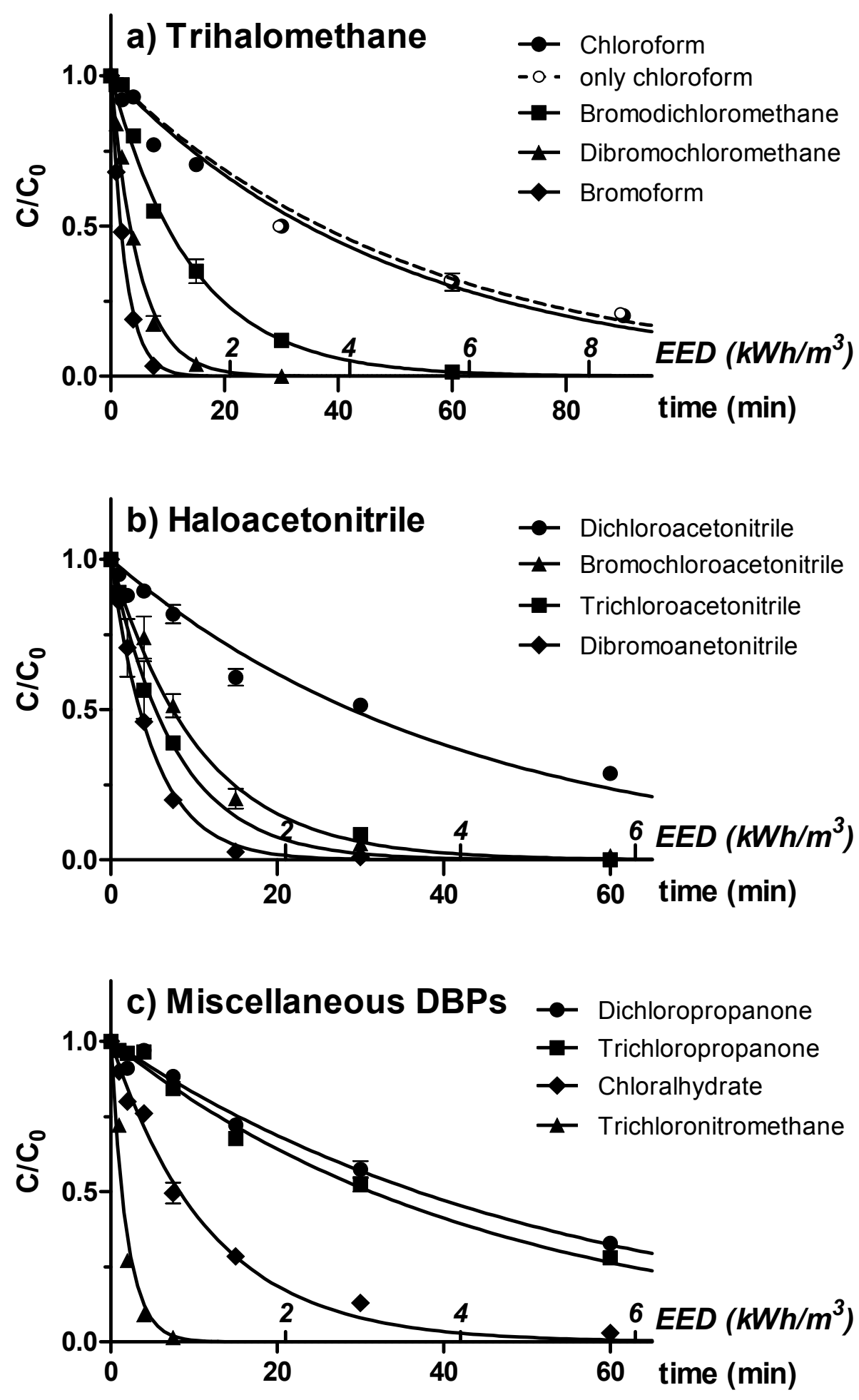

Fig. 3. The removal of the investigated DBPs and the fitted lines according to first order kinetic (Eq. 2). The second horizontal axis (italics) indicates the estimated equivalent energy in full scale treatment. The error bars gives the standard error of the mean. 
Hansen et al. 2013. Science of the Total Environment, 443, pp. 850-856.

http://dx.doi.org/10.1016/j.scitotenv.2012.11.064

Results shown in Fig. 3(a, b, c) were obtained using a mixture of all investigated DBPs. Since it was suspected that chloroform could not only be removed by UV light but also be generated as a degradation product from some of the other DBPs (namely the HANs and the chloral hydrate) following exposure to UV light, a new set of 3 experiments were performed; with THMs alone, a mixture of HANs and with only chloral hydrate under identical experimental conditions. Removal of chloroform from THMs only showed identical results to those obtained using a mix of all investigated DBPs (results shown as open symbols in Fig. 3a). The formation of chloroform from other DBPs (chloral hydrate, trichloropropanone, trichloronitromethane and trichloroacetonitrile) was investigated by irradiation of a solution containing the mixture of HANs and another solution containing chloral hydrate. The HAN mixture contained a small amount of chloroform therefore the start concentration of chloroform was $33 \mu \mathrm{g} \mathrm{L}^{-1}$. After $20 \mathrm{~min}$ of UV treatment the chloroform concentration was $14 \mu \mathrm{g} \mathrm{L}^{-1}$ which concurs with the removal rate determined. Neither the start solution of chloral hydrate nor the solution after $20 \mathrm{~min}$ contained any detectable concentration of chloroform $\left(\mathrm{LOD}=0.50 \mu \mathrm{g} \mathrm{L}^{-1}\right)$. Thus, no formation of chloroform was observed from the mixture of HANs or the chloral hydrate solution. Removal levels for DBPs in both solutions were identical to those obtained with the mixture of all investigated compounds.

Table 1. First order kinetic constants with $95 \%$ confidence intervals (CI) according to Eq. 2 of the investigated DBPs (temperature $=26^{\circ} \mathrm{C}$ ).

\begin{tabular}{|c|c|c|c|c|}
\hline & Compound & $\begin{array}{l}\text { Chemical } \\
\text { Structures }\end{array}$ & $\begin{array}{c}\mathrm{k} \pm 95 \% \mathrm{CI} \\
\left(\mathrm{min}^{-1}\right)\end{array}$ & $\mathrm{R}^{2}$ \\
\hline \multirow{4}{*}{ THMs } & Chloroform & $\mathrm{CHCl}_{3}$ & $0.020 \pm 0.002$ & 0.98 \\
\hline & Bromodichloromethane & $\mathrm{CHBrCl}_{2}$ & $0.070 \pm 0.008$ & 0.99 \\
\hline & Dibromochloromethane & $\mathrm{CHBr}_{2} \mathrm{Cl}$ & $0.205 \pm 0.022$ & 0.99 \\
\hline & Bromoform & $\mathrm{CHBr}_{3}$ & $0.394 \pm 0.026$ & 1.00 \\
\hline \multirow{4}{*}{ HANs } & Dichloroacetonitrile & $\mathrm{CHCl}_{2} \mathrm{CN}$ & $0.024 \pm 0.006$ & 0.94 \\
\hline & Bromochloroacetonitrile & $\mathrm{CHBrClCN}$ & $0.094 \pm 0.010$ & 0.98 \\
\hline & Dibromoacetonitrile & $\mathrm{CHBr}_{2} \mathrm{CN}$ & $0.200 \pm 0.021$ & 0.99 \\
\hline & Trichloroacetonitrile & $\mathrm{CCl}_{3} \mathrm{CN}$ & $0.130 \pm 0.021$ & 0.98 \\
\hline \multirow{4}{*}{$\begin{array}{l}\text { Misc. } \\
\text { DBPs }\end{array}$} & Trichloronitromethane & $\mathrm{CCl}_{3} \mathrm{NO}_{2}$ & $0.523 \pm 0.145$ & 0.99 \\
\hline & Dichloropropanone & $\mathrm{CHCl}_{2} \mathrm{COCH}_{3}$ & $0.019 \pm 0.001$ & 0.98 \\
\hline & Trichloropropanone & $\mathrm{CCl}_{3} \mathrm{COCH}_{3}$ & $0.022 \pm 0.001$ & 0.99 \\
\hline & Chloral hydrate & $\mathrm{CCl}_{3} \mathrm{CH}(\mathrm{OH})_{2}$ & $0.084 \pm 0.009$ & 0.99 \\
\hline
\end{tabular}

\subsubsection{Removal of haloacetonitriles}

As seen in Fig. 3b, dibromoacetonitrile was removed faster than bromochloroacetonitrile and dichloroacetonitrile was the most recalcitrant of the dihalogenated acetonitriles to remove (Table 1). Thus replacing chlorine with bromine increased the photolytic decay of HANs in a similar manner to THMs. The similar effect of bromine substitution was predicted for HANs using QSAR based on solar light (Chen et al., 2010). Trichloroacetonitrile was removed faster than dichloroacetonitrile by UV with a rate constant $(\mathrm{k})$ higher than reported for solar 
Hansen et al. 2013. Science of the Total Environment, 443, pp. 850-856.

http://dx.doi.org/10.1016/j.scitotenv.2012.11.064

light (Chen et al., 2010). This may be due to the higher amount of radiation produced in the UV range by the lamp, compared to that obtained from solar light in conjunction with a higher light intensity achieved in the laboratory setup. However, the ratio of $\log \left(\mathrm{k}_{\text {trichloroacetonitrile }}\right) / \log \left(\mathrm{k}_{\text {dichloroacetonitrile }}\right)$ was 1.8 which was close to the prediction by Chen et al. (2010) using QSAR based on solar light $\left(\log \left(\mathrm{k}_{\text {trichloroacetonitrile }}\right) / \log \left(\mathrm{k}_{\text {dichloroacetonitrile }}\right)=1.5\right)$.

\subsubsection{Removal of miscellaneous DBPs}

The kinetic constants determined for removal of di- and trichloropropanone by UV treatment were very similar (and around the same value as for chloroform) despite the difference in the number of chlorine atoms present (Fig. $3 \mathrm{c}$ and Table 1). One would expect trichloropropanone to be removed faster than dichloropropanone as observed for HANs. However, QSAR prediction of solar photolysis estimated photolysis kinetics of trichloropropanone and dichloropropanone to be similar (Chen et al., 2010).

Removal of chloral hydrate and trichloronitromethane by UV irradiation was also achieved, with trichloronitromethane observed to be the most sensitive compound investigated (Table 1).

\subsubsection{Classification of DBP sensitivity to photolysis}

The functional group present in DBPs had a significant influence on removal kinetics (Table 1). DBPs containing a nitro group (trichloronitromethane) were found to be the most susceptible to UV removal. Comparing removal rates of trichloronitromethane, trichloroacetonitrile, chloral hydrate, trichloropropanone and chloroform it can be concluded that the rankings for the functional groups (referred to the removal rate) was as follows: nitro $\left(\mathrm{NO}_{2}, \mathrm{k}=0.523 \mathrm{~min}^{-1}\right)>\operatorname{nitrile}\left(\mathrm{CN}, \mathrm{k}=0.130 \mathrm{~min}^{-1}\right)>$ hydroxyl $\left(\mathrm{OH}, \mathrm{k}=0.08 \mathrm{~min}^{-1}\right)>$ carbonyl $\left(\mathrm{C}=\mathrm{O}, \mathrm{k}=0.022 \mathrm{~min}^{-1}\right) \approx \operatorname{hydrogen}\left(\mathrm{H}, \mathrm{k}=0.020 \mathrm{~min}^{-1}\right)$. These results are in accordance with those previously predicted in literature from solar photolysis experiments (Chen et al., 2010).

\subsection{Effect of available free chlorine.}

Free chlorine can be photolysed by $\mathrm{UV}$ and $\mathrm{Cl}^{\circ}$ and ${ }^{\circ} \mathrm{OH}$ radicals are formed (Bolton, 2010; Nowell and Hoigne, 1992). These radicals may then degrade DBPs in a secondary photolysis reaction. The possibility of secondary photolysis was investigated by adding $5 \mathrm{mg} \mathrm{L}^{-1}$ of chlorine to a sample containing a mixture of all investigated DBPs and subsequent exposure to UV irradiation for $3 \mathrm{~min}$. Free chlorine was removed completely in the $3 \mathrm{~min}$., but removal of the 12 investigated DBPs did not increase (Supplementary material, Fig. S1). Treatment with $5 \mathrm{mg} \mathrm{L}^{-1} \mathrm{Cl}_{2}$ for $3 \mathrm{~min}$ was then repeated 3 consecutive times thus UV exposure was in total $9 \mathrm{~min}$ and $15 \mathrm{mg} \mathrm{L}^{-1}$ chlorine added. An increase in DBP removal however was not observed compared to what could be expected from photolysis alone. This may be due to the high number of halogens on each of the DBPs which shield the carbon atoms from radical attack. This subsequently leads to some DBPs (e.g. trihalomethanes) having a lower reaction 
Hansen et al. 2013. Science of the Total Environment, 443, pp. 850-856.

http://dx.doi.org/10.1016/j.scitotenv.2012.11.064

rate constant for reactions involving hydroxyl radicals compared to most organic molecules (Bolton, 2010).

\subsection{Electric energy per order (EEO)}

Since irradiation time may be converted to electrical energy dose as described above, the EEO for the investigated DBPs can be estimated. As for the characterisation of the full scale system, plots of normalized DBP concentration versus EED were used for EEO determination by least square fit according to Eq. 1. The obtained values however (Table 2) are estimations since the EED was indirectly estimated by photolysis of combined chlorine from swimming pool water. High values of EEO indicate that a large amount of energy is required to remove the compound.

Table 2. The estimated values of EEO along with the $\mathrm{C} / \mathrm{Ci}$ and the removal calculated with a treatment dose of $1.34 \mathrm{kWh} \mathrm{m}^{-3}$.

\begin{tabular}{llccc}
\hline & EEO $\left(\mathrm{kWh} \mathrm{m}^{-3}\right)$ & $\mathrm{C} \mathrm{C}_{\mathrm{i}}$ & $\begin{array}{c}\text { Removal } \\
\text { per day \% }\end{array}$ \\
\hline \multirow{3}{*}{ THMs } & Combined chlorine & 1.0 & 0.05 & 95 \\
& Chloroform & 11 & 0.75 & 25 \\
& Bromodichloromethane & 3.1 & 0.37 & 63 \\
& Dibromochloromethane & 1.1 & 0.06 & 94 \\
& Bromoform & 0.6 & 0.00 & 100 \\
\hline \multirow{3}{*}{ HANs } & Dichloroacetonitrile & 9.1 & 0.71 & 29 \\
& Bromochloroacetonitrile & 2.3 & 0.27 & 73 \\
& Dibromoacetonitrile & 1.1 & 0.06 & 94 \\
& Trichloroacetonitrile & 1.7 & 0.16 & 84 \\
\hline \multirow{3}{*}{ Misc. DBPs } & Trichloronitromethane & 0.4 & 0.00 & 100 \\
& Dichloropropanone & 12 & 0.77 & 23 \\
& Trichloropropanone & 9.9 & 0.73 & 27 \\
& Chloral hydrate & 2.6 & 0.31 & 69 \\
\hline
\end{tabular}

\subsection{Estimation of DBP removal by typical UV treatment}

The UV system in the warm water pool in Gladsaxe swimming pool consisted of 4 UV lamps (each $0.7 \mathrm{~kW}$ ) running $24 \mathrm{~h}$ per day with a total pool volume of $50 \mathrm{~m}^{3}$. This gives an applied electrical energy dose from UV of $1.34 \mathrm{kWh} \mathrm{m}^{-3} \mathrm{~d}^{-1}$. Considering UV treatment as the only removal process affecting the investigated DBPs, the removal achieved by applying UV treatment in a real swimming pool can be estimated using Eq. 1 . The removal $\left(1-\mathrm{C}_{\text {out }} / \mathrm{C}_{\text {in }}\right)$ of each DBP with EED $=1.34 \mathrm{kWh} \mathrm{m}^{-3} \mathrm{~d}^{-1}$ and EEO as found in this paper was estimated (Table 2). Chloroform, dichloroacetonotrile, and di- and trichloropropanone can be expected to exhibit a removal of less than $30 \%$ of the initial concentration per day while the rest of the investigated DBPs are expected to exhibit more than $63 \%$ removal, with some being $100 \%$ of the initial concentration per day. 
Hansen et al. 2013. Science of the Total Environment, 443, pp. 850-856.

http://dx.doi.org/10.1016/j.scitotenv.2012.11.064

However, in a swimming pool setting other processes such as formation, volatilisation and degradation will affect the concentration of DBPs. For the very volatile DBPs, like chloroform and trichloroacetonitrile, it can be expected that photolysis has a relatively low importance for the fate of the DBP compared to the volatilisation. Conversely chloral hydrate, which was photolysed at a medium rate, is described as being very stable in water because it hydrolyzes very slowly at neutral $\mathrm{pH}$, reacts slowly with chlorine and is not volatile (Brunet et al., 2010).

It was predicted that $95 \%$ of the combined chlorine could be removed by UV treatment for one day. However, in a test of the UV system in Gladsaxe swimming pool over several weeks a decrease of $67 \%$ in the equilibrium concentration of combined chlorine in the pool basin was achieved (Kristensen et al., 2009; Kristensen et al., 2010).

In conclusion, UV treatment for combined chlorine control may result in significant removal of trichloronitromethane, chloral hydrate and the bromine containing haloacetonitriles and trihalomethanes due to their UV sensitivity. However, in order to quantify the effect of UV treatment on pool water concentrations, formation rates and rates for competing removal processes (e.g. evaporation, further oxidation by chlorine or hydrolysis) need to be quantified. To the best of our knowledge, descriptions of these processes in swimming pools are not available in the literature.

\section{Conclusions}

- The first order kinetic constant for photolysis by UV irradiation was determined for the 12 DBPs. The constant ranged from $0.020 \mathrm{~min}^{-1}$ for chloroform to $0.523 \mathrm{~min}^{-1}$ for trichloronitromethane and generally increased with bromine substitution.

- The electrical energy per order (EEO) was estimated for each of the investigated compounds. The combined chlorine in swimming pool water required $1.0 \mathrm{kWh} \mathrm{m}^{-3}$ to achieve $90 \%$ removal whereas chloroform and trichloronitromethane required 11 and $0.4 \mathrm{kWh} \mathrm{m}^{-3}$, respectively.

- Comparing applied UV dosage used for combined chlorine removal with degradation effectiveness suggests significant removal of trichloronitromethane, chloral hydrate and the bromine containing haloacetonitriles and trihalomethanes as a beneficial sideeffect of chloramine control by UV.

\section{Acknowlegment}

The authors thank Scan Research A/S for donating the laboratory UV system for the study and assisting with the analysis of combined chlorine in the investigation of the full scale system. Furthermore the assistance of the staff at Gladsaxe public swimming pools for tests of the full scale system and supplying samples of pool water for laboratory experiments is appreciated. The authors also acknowledge financial support from the Comunidad Autonoma de Madrid provided throughout project CARESOIL (S2009AMB-1648) and from the Spanish 
Hansen et al. 2013. Science of the Total Environment, 443, pp. 850-856.

http://dx.doi.org/10.1016/j.scitotenv.2012.11.064

Ministry of Science and Innovation, project CTM2010-16693. This investigation is funded by the Danish Agency for Science Technology and Innovation via The Knowledge Coupon programme (Videnkupon). Kamilla M.S. Hansen is grateful for a fully funded $\mathrm{PhD}$ stipend by DTU Environment to support this work. The work was further supported by the Graduate School Urban Water Technology (www.urbanwatertech.dk).

\section{Appendix A. Supplementary material}

Supplementary material to this article can be found online at http://dx.doi.org/10.1016/j.scitotenv.2012.11.064

\section{References}

Bernard A, Carbonnelle S, Dumont X, Nickmilder M. Infant swimming practice, pulmonary epithelium integrity, and the risk of allergic and respiratory diseases later in childhood. Pediatrics 2007;119:1095-103.

Beyer A, Worner H, van Lierop R. The use of UV for destruction of combined chlorine [technical note]. Wallace \& Tiernan 2004.

Available online at: http://www.pwtag.org/researchdocs/Used $\% 20$ Ref $\% 20$ docs $/ 25 \% 20$ the use of uv for d estruction_of_combined_chlorine\%20Wallace\%20and\%20Tiernan.pdf Accessed 22 June 2012

Bolton JR. Ultravioulet Applications Handsbook. 3rd ed. Canada: ICC Lifelong Learn Inc., Edmonton; 2010.

Brunet R, Berne F, De Laat J. Disinfection by-products in chlorinated swimming pool waters (In French: Sous-produits de chloration dans les eaux de piscines publiques). L'Eau, L'Industrie, Les Nuisances 2010;333:83-8. Available from: http://www.revueein.com/article-EIN/2869/Sousproduits_de_chloration_dans_les_eaux_de_piscines_publiques/?string=

Cassan D, Mercier B, Castex F, Rambaud A. Effects of medium-pressure UV lamps radiation on water quality in a chlorinated indoor swimming pool. Chemosphere 2006;62:150713.

Cassan D, Mercier B, Castex F, Rambaud A. Nitrogen trichloride levels in air in chlorinated indoor swimming pools treated by medium-pressure UV radiation. In proceeding of IOA IUVA World Congress \& Exhibition, Paris, France; 2011

Chen B, Lee W, Westerhoff PK, Krasner SW, Herckes P. Solar photolysis kinetics of disinfection byproducts. Water Res 2010;44:3401-9.

Chiswell B, Wildsoet CF. The causes of eye irritation in swimming pools. Water Sci Technol 1989;21:241-4. 
Hansen et al. 2013. Science of the Total Environment, 443, pp. 850-856.

http://dx.doi.org/10.1016/j.scitotenv.2012.11.064

De Laat J, Berne F. La déchloramination des eaux de piscines par irradiation UV. Étude bibliographique [Theoretical and practical aspects of the dechloramination of swimming pool water by UV irradiation]. Eur J Water Quality 2009;40(2):129-49. French http://dx.doi.org/10.1051/water/2009009

Erdinger L, Kirsch F, Sonntag HG. Irritating effects of disinfection by-products in swimming pools. Zbl Hyg Umweltmed 1998;200:491-503.

Goodman M, Hays S. Asthma and swimming: a meta-analysis. J Asthma 2008;45:639-47.

Glauner T, Kunz F, Zwiener C, Frimmel FH. Elimination of swimming pool water disinfection by-products with advanced oxidation processes (AOPs). Acta Hydroch Hydrob 2005;33:585-94.

Hansen KMS, Willach S, Mosbæk H, Andersen HR. Particles in swimming pool filters Does pH determine the DBP formation? Chemosphere 2012a;87:241-7.

Hansen KMS, Willach S, Antoniou MG, Mosbæk H, Albrechtsen H-J, Andersen HR. Effect of $\mathrm{pH}$ on the formation of disinfection byproducts in swimming pool water - Is less THM better? Water Res 2012b;46:6399-409.

Hery M, Hecht G, Gerber JM, Gendre JC, Hubert G, Rebuffaud J. Exposure to chloramines in the atmosphere of indoor swimming pools. Ann Occup Hyg 1995;39:427-39.

Jin J, Gamal El-Din M, Bolton JR. Assessment of the UV/ chlorine process as an advanced oxidation process. Water Res 2011;45(4):1890-6

Keuten MGA, Schets FM, Schijven JF, Verberk JQJC, van Dijk JC. Definition and quantification of initial anthropogenic pollutant release in swimming pools. Water Res 2012;46:3682-92.

Kristensen GH, Klausen MM, Andersen HR. Afprøvning af forskellige renseteknologier på svømmebade [Testing of different treatment technologies in swimming pools]. Danish Nature Agency, Ministry of the Environment, Denmark 2010. Danish Available online at: http://www.naturstyrelsen.dk/NR/rdonlyres/A67BEA31-89814210-AC8B-

A8811CDAB796/0/Afprovningafforskelligerenseteknologierpaasvommebade.pdf Accessed 22 June 2012

Kristensen GH, Klausen MM, Andersen HR, Erdinger L, Lauritsen FR, Arvin E, et al. Full scale test of UV-based water treatment technologies at Gladsaxe Sportcentre - with and without advanced oxidation mechanisms. In: Proceeding of the Third International Swimming Pool and Spa Conference, 2009 March 17-20; London, United Kingdom. Available online at: http://www.pwtag.org/researchdocs/Used\%20Ref\%20docs/6\%20Paper\%204.1\%20UV \%20\&\%20THMs\%20Denmark.pdf Accessed 21 June 2012 
Hansen et al. 2013. Science of the Total Environment, 443, pp. 850-856.

http://dx.doi.org/10.1016/j.scitotenv.2012.11.064

Kristensen GH, Klausen MM, Janning K. Forsøgsdrift af varmtvandsbassin i Gladsaxe Svømmehal ved lavt indhold af frit klor og reduceret $\mathrm{pH}$ [Experimental operation of a warm water pool in Glasaxe swimming pool at low chlorine level and $\mathrm{pH}$ ]. Report from DHI, Denmark 2007. www.dhigroup.com. Danish.

Lekkas TD, Nikolaou AD. Degradation of disinfection byproducts in drinking water. Environ Eng Sci 2004;21:493-506.

Li J, Blatchley ER. Volatile disinfection byproduct formation resulting from chlorination of organic-nitrogen precursors in swimming pools. Environ Sci Technol 2007;41:6732-9.

Li J, Blatchley ER. UV photodegradation of inorganic chloramines. Environ Sci Technol 2009;43: 60-5.

Liviac D, Wagner ED, Mitch WA, Altonji MJ, Plewa MJ. Genotoxicity of water concentrates from recreational pools after various disinfection methods. Environ Sci Technol 2010;44:3527-32.

Massin N, Bohadana AB, Wild P, Hery M, Toamain JP, Hubert G. Respiratory symptoms and bronchial responsiveness in lifeguards exposed to nitrogen trichloride in indoor swimming pools. Occup Env Med 1998;55:258-63.

Nicole I, De Laat J, Dore M, Duguet JP, Suty H. Etude de la degradation des trihalomethanes en milieu aqueux dilue par irradiation UV - determination du rendement quantique de photolyse a 253,7 nm. Environ Technol 1991;12:21-31.

Nowell LH, Hoigne J. Photolysis of aqueous chlorine at sunlight and ultraviolet wavelengths - II. Hydroxyl radical production. Water Res 1992;26:599-605.

Richardson SD, DeMarini DM, Kogevinas M, Fernandez P, Marco E, Lourencetti C, et al. What's in the pool? A comprehensive identification of disinfection by-products and assessment of mutagenicity of chlorinated and brominated swimming pool water. Environ Health Persp 2010;118:1523-30.

Rudra A, Thacker NP, Pande SP. Hydrogen peroxide and ultraviolet irradiations in water treatment. Environ Monit Assess 2005;109:189-97.

Schmalz C, Wunderlich HG, Heinze R, Frimmel FH, Zwiener C, Grummt T. Application of an optimized system for the well-defined exposure of human lung cells to trichloramine and indoor pool air. J Water Health 2011;9:586-96.

Sichel C, Garcia C, Andre K. Feasibility studies: UV/chlorine advanced oxidation treatment for the removal of emerging contaminants. Water Res 2011;45(19):6371-80.

Stefan MI, Bolton JR. Fundamental approach to the fluence-based kinetic and electrical energy efficiency parameters in photochemical degradation reactions: polychromatic light. J Environ Eng Sci 2005;4(S1):S13-8.

Thickett KM, McCoach JS, Gerber JM, Sadhra S, Burge PS. Occupational asthma caused by chloramines in indoor swimming-pool air. Eur Respir J 2002;19:827-32. 
Hansen et al. 2013. Science of the Total Environment, 443, pp. 850-856.

http://dx.doi.org/10.1016/j.scitotenv.2012.11.064

Villanueva CM, Cantor KP, Grimalt JO, Malats N, Silverman D, Tardon A, et al. Bladder cancer and exposure to water disinfection by-products through ingestion, bathing, showering, and swimming in pools. Am J Epidemiol 2007;165:148-56.

White GC. Handbook of chlorination and alternative disinfectants. 3rd ed. New York: Van Nostrand Reinhold; 1992.

WHO. Guidelines for safe recreational water environments. Volume 2, Swimming pools and similar environments, Geneva, Switzerland: World Health Organization, WHO Press; 2006.

Zwiener C, Richardson SD, DeMarini DM, Grummt T, Glauner T, Frimmel FH. Drowning in disinfection byproducts? Assessing swimming pool water. Environ Sci Technol 2007;41:363-372. 